\title{
A Relational Model for Stress: A Systematic Review of the Risk and Protective Factors for Stress-Related Diseases in Firefighters
}

\author{
Joana Proença Becker ${ }^{1} * \mathbb{D}^{\mathbb{D}}$, Rui Paixão ${ }^{1}$ and Manuel João Quartilho $^{2}$ \\ 1 Faculty of Psychology and Education Sciences of the University of Coimbra, 3001-802 Coimbra, Portugal; \\ rpaixao@fpce.uc.pt \\ 2 Faculty of Medicine of the University of Coimbra, 3004-504 Coimbra, Portugal; mjquarti@ci.uc.pt \\ * Correspondence: joanapbecker@gmail.com
}

Received: 14 January 2020; Accepted: 26 February 2020; Published: 28 February 2020

check for updates

\begin{abstract}
Firefighters are considered a high-risk group for the development of PTSD and other stress-related diseases. More than the exposure to potentially traumatic events, personal and occupational characteristics have been pointed out as interfering in the perception of stress, which may lead to the emergence of mental and physical symptoms. This study aimed to analyze the relationship between the main factors that contribute to stress-related diseases in firefighters. A systematic review was conducted in order to identify original articles focusing on risk and protective factors for stress in this population. Personality traits, training, experience in extreme situations and social and organizational support influence the perception of stress and, consequently, the choice of coping strategies, which may protect against or potentiate the stress reactions. The findings of this study allow us to draw a relational model that represents the dynamics among the factors related to stress in firefighters. The development of PTSD and other stress-related diseases depends on a host of pre-trauma and post-trauma factors and, although training is an important protective factor, being prepared to face extreme situations does not mean being immune to traumatic stress.
\end{abstract}

Keywords: PTSD; stress-related diseases; firefighters; relational model; systematic review

\section{Introduction}

In recent years, different countries have been affected by multiple catastrophes, such as the severe fires in California, Australia and Europe (Greece and Portugal), with the destruction of hundreds of homes and lives. Subsequently, the firefighters who are exposed to these potentially traumatic events have become a group of interest of those who research traumatic stress in catastrophe scenarios [1]. These professionals face a work routine that goes beyond forest fires, such as helping victims of different accidents and even responding to medical emergencies, the so-called crisis situations.

Previous studies [2] have indicated that professionals who work in crisis and catastrophe scenarios may experience stress reactions, somatic symptoms, fatigue, post-traumatic stress disorder (PTSD), depression, anxiety, and alcohol abuse. These symptoms are often consequences of maladaptive coping strategies such as denial and avoidance, applied by the fear of stigma related to mental illness and the will to meet the expectations placed on these professionals. Although most research in this field has suggested that repeated exposure to stress is one of the main reasons leading professionals to develop stress-related diseases [3,4], some studies have emphasized that firefighters, due to their training and experience, are more protected from being affected by stress reactions than the general population, explaining why that volunteers have higher PTSD rates than professionals [2].

In addition to the divergences regarding the consequences of exposure to stress in firefighters [2,3], the updating of the Diagnostic and Statistical Manual of Mental Disorders (DSM) is also a factor 
which may influence the understanding on traumatic stress of professionals who work in crisis and catastrophe scenarios. Although the PTSD diagnosis remains largely consistent, it has been changed in successive versions of DSM. While in the DSM-III "traumatic events were described as those that occur outside the range of usual human experience", the DSM-IV and DSM-IV-R described them as "involving actual or threatened death or serious injury, or threat to the physical integrity of self or others", as well as "an emotional response of fear, helplessness, or horror" [5] (p. 25). In the latest version of the manual, the DSM-5 [6], the main change can be considered the addition of a new criterion, namely negative alteration in cognition and mood, which highlights symptoms such as the persistent negative emotional state (e.g., anger, shame, or guilt) and the persistent distorted cognition about the variables of traumatic events that may lead victims to blame themselves or others.

In the face of data inconsistency and the scarcity of research in this field $[3,5,7]$ we were interested in identifying the risk and protective factors for the development of PTSD and other stress-related diseases in firefighters. In this study, the notion of risk and protective factors are defined as described by the Institute of Medicine [8] (p. 59)—“'factors that preceded the exposure to trauma, factors associated with the trauma exposure itself, and factors associated with the recovery environment".

The purpose of this review was to answer the following questions: What is determinant for the development of PTSD and other stress-related diseases in firefighters? Are there factors that outweigh the event intensity and violence? How do these factors relate to each other?

\section{Materials and Methods}

This study was based on PICOS criteria, and adheres to PRISMA guidelines [9] (Supplementary Figure S1: presents the PRISMA flow diagram).

\subsection{Eligibility}

Considering the fact that the American Psychiatric Association (APA) added PTSD to the third edition of its Diagnostic and Statistical Manual of Mental Disorders (DSM-III) nosologic classification scheme, a search was conducted in order to identify the number of publications on PTSD and firefighters since 1980, the year this diagnosis was introduced into the Manual. This survey aimed to determine the period of the current systematic review, adopting the year in which the progressive increase in research in this field began as a starting point for the selection of articles for analysis. There has been a significant increase in the number of publications on PTSD and firefighters since 2013 in all databases included in this survey, constituting therefore the first eligibility criterion of this review (Supplementary Figure S2 presents the graphic of publications on PTSD and firefighters 1980-2019).

Having defined the search period, the other eligibility criteria for studies to be included were: (1) original studies focused on (2) traumatic stress in firefighters, (3) mentioning the risk and protective factors for the development of PTSD and stress-related diseases. Studies that analyzed alternative therapies (yoga or meditation) and the validation of scales and tests involving medication were excluded.

\subsection{Information Source and Search}

A comprehensive systematic review was conducted by the main author of the current study in the Health and Social Care, ProQuest Psychology Journals, PsycARTICLES, PubMed and Web of Science, using the keywords "PTSD and firefighters", "traumatic stress and professionals" and "somatization and professionals" (abstract or topic). Filters were used to exclude systematic reviews (NOT "systematic review" - title) and to include only articles mentioning firefighters (AND "firefighters" - anywhere/all fields). In this survey, 558 studies were identified. After the exclusion of duplicates and the reading of the abstracts, 52 articles met the eligibility criteria.

\section{Results}

All the studies were based on a cross-sectional design, with forty-six being through the application of self-report questionnaires as the single method of evaluation. In the selected articles, more than 
traumatic stress or the PTSD diagnosis, the risk and protective factors and symptoms presented by firefighters were the main themes addressed (Supplementary Table S1 presents a summary of 52 studies on PTSD and stress-related diseases in firefighters). Regarding PTSD rates, deviations were verified-while some studies reported PTSD rates of 26.6\% [10] and 31.8\% [11] among firefighters, others indicated $13 \%$ [12], or even $2.7 \%$ [13]. The reasons for a such variation in PTSD prevalence may be related to: the location of data collection, such as when it occurred inside fire departments-due to the lack of homogeneity in samples in relation to the risk faced or, when they are homogeneous, the workplace may inhibit the emotional manifestations [14]; cultural characteristics [15]; or fear of stigma, a common aspect among these professionals [16-19]. In addition to presenting evidence for the prevalence of PTSD, the symptoms recurrently mentioned by studies were depression $(\mathrm{N}=16)$, alcohol abuse $(\mathrm{N}=11)$, suicidal ideation or behaviors $(\mathrm{N}=10)$ and avoidance $(\mathrm{N}=6)$. All these stress-related symptoms were directly or indirectly influenced by personality traits, working conditions and maladaptive coping strategies [20-26]. Strictly speaking, the perpetuation of trauma exceeds exposure to potentially traumatic events, as it is also influenced by personal and occupational characteristics, organizational structure, interpersonal relationships and mental and physical health conditions $[12,14,27,28]$.

Through this analysis, we identified the main risk and protective factors for the development of PTSD and other stress-related diseases in firefighters as being the perception of stress, social and organizational support, training and experience, usually associated with being a volunteer or professional firefighter, and the choice of coping strategies. These factors influence each other, offering evidence that stress-related diseases are the result of a set of failures that may occur before, during and after potentially traumatic events [12,14,16,27,29-32].

\subsection{The Perception of Stress}

There is a consensus that professionals who work in crisis and catastrophe contexts configure a high-risk group for the development of stress-related diseases. However, the analyzed studies pointed out that, to a greater extent than the severity and exposure time to a potentially traumatic event, personal characteristics interfere in the perception of stress or threat and, consequently, in the emergence of mental and physical issues [13,32-37]. The subjective appraisal and the perception of stress may contribute to negative consequences in mental health, such as depression, sleep disorders and alcohol abuse $[1,24,31,33]$. The perception of stress, in addition to the limitation of resources facing a potentially traumatic event, may lead to dissociation experiences, which influence the consolidation of the traumatic memory and, subsequently, the development of stress-related symptoms. The findings also indicate that training and increased experience from different kinds of crisis and catastrophe scenario may protect from the development of PTSD [23,35].

Furthermore, the subjective perception about traumatic events was associated with so-called post-traumatic growth (PTG). According to supporters of this theory, PTG is more than returning to homeostasis after facing stressful events (referred to as resilience) - it is to be transformed by trauma and to reach a higher level of functioning, with changes in the view of yourself and the world. In the same sense, the authors stated that subjective appraisal can make the scenario more manageable if the victims evaluate their lives positively during negative conditions, which may be facilitated by their environment $[25,29,38-40]$.

\subsection{Social and Organizational Support}

While the subjective appraisal of a potentially traumatic event is a relevant factor for the development of stress-related diseases, or the protection against them, social support is directly related to the way of looking at life and, consequently, to the perception of stress [41-43]. The current survey revealed that the presence of social support not only protects against the development of stress-related diseases, but also attenuates the association of stress-related symptoms with suicidal ideation by influencing the subject's interpretation of the event and the choice of coping strategies [11]. 
Although there is an agreement regarding the role of support from family and friends, the organizational support, in terms of relationships with leaders and peers, is underlined as essential to overcome crisis situations [36,42,44]. The role of social support inside departments/organizations was highlighted, offering evidence that both training and the perception of organizational support reduce the risks of developing stress-related diseases. This perspective was emphasized when considering the differences between professional and volunteer firefighters $[23,35,45]$.

\subsection{Professionals and Volunteers}

Most analyzed studies began by stating that professionals who work in crisis and catastrophe scenarios are recurrently exposed to traumatic events and have a great risk of developing stress-related diseases $[13,15-17,26,46]$. However, some studies presented low rates of PTSD in firefighters, giving cultural issues and the fear of stigma as the reasons for these results [14-16]. In addition, training and organizational support were indicated as the most relevant factors when comparing results between professional and volunteer firefighters.

In the current review, only two studies focusing on the differences between professional and volunteer firefighters were found, presenting opposite results regarding the level of distress, although volunteers were shown to have a higher risk of developing stress-related diseases than professionals in both studies $[17,23]$ Both studies were based on the same factors, finding that organizational support, the sense of control (through the clear instructions of the situation and tasks to be performed), and training for dealing with extreme situations are protective factors against the development of stress-related diseases. The lack of appropriate training and the uncertainties regarding the tasks and the situations that they were faced with aroused the perception of threat that, together with the lack of social and organizational support, led to stress reactions. The research of Brazil (2017) corroborated that these operational aspects and lack of communication and collaboration among firefighters may increase the severity of the consequences from critical incidents. On the other hand, this author indicated that the interpersonal nature also interferes negatively in the perception of stress, which contradicts the position of Haraldsdóttir et al. [23], who suggested that volunteers who were part of the community had not been affected by this factor. Although the interpersonal nature of rescue work was not considered a relevant factor, the same study found that volunteers used more avoidance coping and emotional coping measures, and less rational coping measures than professionals.

Whether volunteer or professional firefighters, the lack of training and experience, as well as a lesser sense of belongingness, influence the subjective perception of stress, increasing distress reactions. The higher PTSD rate among volunteers was related to a lack of physical, mental and emotional training, while learning to deal with daily work, and possible emergencies, explained the lower vulnerability among professionals. In particular, those performing regular roles in crisis and catastrophe scenarios are likely to have received more training and thus be more mentally and skillfully prepared $[1,17,23,36,41]$.

\subsection{Coping}

The abovementioned factors-personality traits, subjective perception, social and organizational support, and occupational conditions-had been mentioned as directly influencing the choice of emotions and actions to deal with a potentially traumatic event $[20,27,47,48]$. Studies have indicated that firefighters constitute a group with a high prevalence of alcohol abuse, of around 30\%, suggesting that substance abuse is a maladaptive coping strategy. According to these findings, firefighters may cope with their pain by consuming alcohol, both as a means of relieving their symptoms and to effectively function during their next shift $[26,35,49,50]$.

Considering the influence of coping styles after traumatic exposure, the studies related maladaptive strategies such as distraction, substance abuse and self-blame to more stress-related symptoms, while problem-focused strategies diminish emotional stress. The maladaptive strategies aim to avoid engagement with the traumatic event, increasing the symptomatic chart $[20,40,45,51]$. Subsequently, 
they may contribute to the belief that the symptoms are dangerous and should be avoided by establishing a negative feedback cycle [16]. Avoidance behaviors were mentioned as increasing the frequency and intensity of traumatic memories, thus resulting in an escalation of distress, which could lead to the application of more avoidance strategies. Although avoidance is a symptom of PTSD, several studies showed that avoidance behavior is also a maladaptive coping strategy, being a risk factor for the development of this pathology, thus recognizing the negative cycle [20,23,45,51-54].

The choice of adaptive coping strategies was presented as a result of a set of factors such as personality traits, camaraderie, feeling of belonging and social support $[36,39,40]$. "The capacity to tolerate chronic stress and navigate challenges is vital for firefighters to prevent behavioral health disorders" such as PTSD [55] (p. 144). Post-traumatic growth (PTG) theory was mentioned in order to explain that exposure to a traumatic event may provide opportunities for positive outcomes. Facing an extreme situation, firefighters may experience increased awareness of life priorities, as well as the fact that they may improve or learn new coping skills and experience new levels of self-efficacy $[29,38,40,45]$. On the other hand, some studies indicated that PTG may be a result of the undertaken coping strategies [20,40]. According to the study by Yang and Ha [40], personality traits make a person more likely to use certain coping strategies. They found that an extroverted personality was related to problem-focused coping, and problem-focused coping after traumatic events was shown to have a significant influence on firefighters' PTG. Moreover, flexibility in the choice of coping strategies was presented as a moderator between traumatic exposure and PTSD symptoms [36,46]. "The ability to flexibly regulate emotions in accordance with changes in contextual demands is associated with the tendency to develop fewer PTSD symptoms over repeated duty-related exposure to trauma" [46] (p. 09).

\section{Discussion}

As mentioned before, although there are studies on PTSD and other stress-related diseases as consequence of facing crisis and catastrophe scenarios, the target population is usually the direct victims of these events, while those who put their well-being aside for the benefit of society have not received the same literary attention $[13,35]$. The current systematic review made it possible to trace the path to the development of stress-related diseases, identifying the main factors which influence the firefighters' reactions facing potentially traumatic events.

\section{A Relational Model for Stress in Firefighters}

The subjective perception is behind all other factors, since those who have experienced an event respond according to their history, culture and beliefs. An extreme event tends to trigger a stress reaction, depending on whether it is perceived as threatening or uncontrollable $[24,32,56]$. Recognizing this, it is possible to assert that "perceived stress partially mediates the relationship between traumatic stress and PTSD symptoms", which means that the "amplification of perceived stress influences the development of PTSD symptoms" [33] (p. 131). If the subjective perception may lead to stress, this may also be a protective factor.

According to Shrira et al. [39] (p. 68), subjective well-being can make the hostile scenarios more manageable "by letting individuals evaluate their lives positively during negative conditions". Subjective well-being "refers to the extent to which people perceive their lives as favorable in terms of satisfaction and happiness". Subjective perception, in addition to being built throughout the individual's development, is also influenced by relationships and cultural and social contexts. Appraising the aspects of the subjective perception, the importance of social and organizational support is justified as contributing to the way in which an individual interprets and deals with adversities, as well as the perception of being supported may reduce the levels of stress [30,42,43,45].

In addition to the abovementioned issues, the variation in PTSD rates among firefighters is also explained through occupational conditions and experience in different crisis scenarios [57-60]. Psarros et al. [1] (p. 20), when analyzing the personality traits and individual factors associated with PTSD, found that "those who worked permanently as firefighters had $70 \%$ lower probability of having 
PTSD as compared to participants who worked temporary as firefighters", associating the training and field experience to the development of stress-related diseases. Armstrong, Shakespeare-Finch, and Shochet [41] (p. 344) stated the importance of belonging to an organization, as is the case of professional firefighters, indicating that a "sense of connection and belongingness provides a lens through which people interpret daily events and incidents". Corroborating both conclusions, in a study on the relationship between PTSD and PTG, Sattler et al. [36] asserted that recurrent exposure to critical incidents teaches firefighters to deal with stressors associated with their professional duties, and that support received within organizations influences the choice of coping strategies.

Taking these factors together, we propose a relational model (Figure 1) of the risk and protective factors for the development of stress-related diseases in firefighters. This model contains subjective and social factors that interact with each other, influencing the perception of stress, considered the central point of this model.

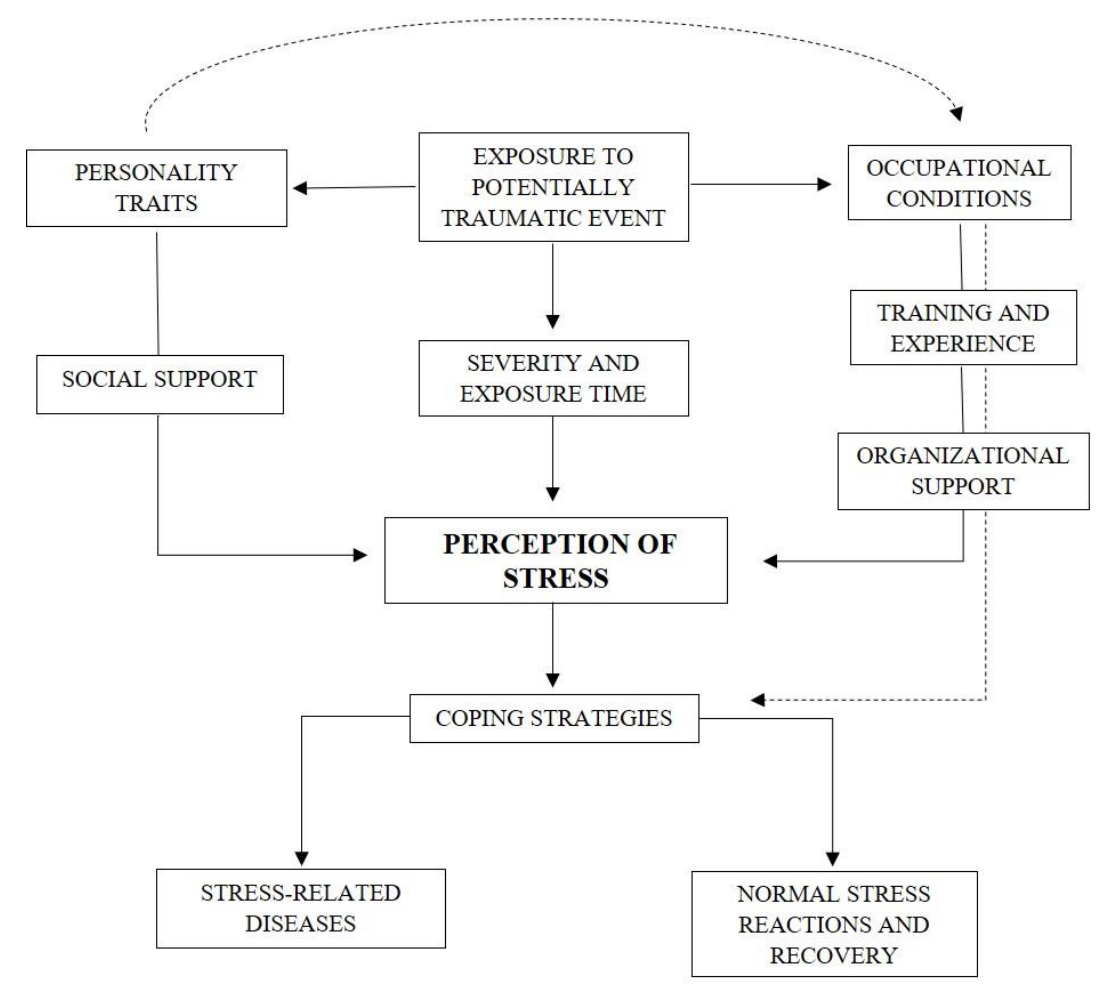

Figure 1. Relational Model for Stress in Firefighters.

The first factor of the proposed model is exposure to a potentially traumatic event, a precondition for stress reactions $[47,53,55,59]$. Indeed, several studies have shown that the source and context of the trauma were related to increased PTSD symptoms $(p<0.05)[1,12,20,28,46]$. Then, the severity and exposure time enter in this model, since trauma load $[10,45]$ and the number of critical incidents $[14,25,31]$ were significantly related to PTSD symptom severity (both $p$ range $<0.01$ to $<0.001)$. Notably, personality traits such as extraversion $(p<0.001)$ [40], impulsivity $(p=0.003)$ [21], optimism $(p<0.05)$ [40], self-forgiveness $(p<0.001)$ [18], distress tolerance $(p<0.001)$ [50], and resiliency $(p<0.001)[24,33,55]$ seem to affect all other variables which influence the perception of stress, thereby affecting the choice of coping strategies. Moreover, personality traits were directly associated with the choice of coping strategies ( $p$ range $<0.05$ to $<0.001$ ) $[21,36,40,44]$, which can lead to either stress-related diseases or normal stress reactions and a recovery process. However, the professional aspects, which include occupational conditions [23,24,34,38], training and experience [12,14,17,29], and organizational support $[36,41,44]$, may assume a relevant role in the subjective appraisal of the event and, subsequently, in the choice of coping strategies to deal with stress. 
Occupational conditions are the most important of the professional factors of the proposed model, since they comprise most of the variables considered likely to reduce or increase stress-related symptoms, such as operational stress $\quad(p$ range $<0.05$ to $<0.001)[20,36,41,48], \quad$ burnout $(p$ range $<0.01$ to $<0.001)[13,24]$, psychophysical exhaustion ( $p$ range $=0.05$ to $<0.001)[22,23,34$ ], time pressure $(p<0.001)$ [23], chronotype $(p<0.001)$ [37] and clarity of mission instructions $(p=0.005)$ [23]. Although studies focused on the influence of training and experience have not been found, these factors were associated with the different reactions of professional and volunteer firefighters after critical events. Volunteer firefighters had a higher risk of depression $(p=0.004)$ [17], anxiety $(p=0.000)$ [23], and PTSD symptoms ( $p$ range $=0.048$ to $<0.001)[1,17,23]$ compared to professional firefighters. These findings were associated with less formal training [17] and work experience ( $p$ range $<0.05$ to $<0.01)[12,23$ ]. Finally, organizational support, from supervisors and co-workers, was associated with fewer PTSD symptoms $(p<0.001)[42,44]$, while the feeling of organizational belongingness was associated with PTG $(p<0.001)[41,44]$.

Regarding social support as a whole, it was highly related to PTSD symptom severity $(p<0.001)[30,36,45]$. Lee's study [30] indicated that the indirect effect of traumatic events on PTSD symptoms through intrusive rumination $(p<0.001)$ and entrapment $(p<0.05)$ differed according to the degree to which individuals perceived social support. Stanley et al. [44] investigated the perceptions of belongingness and social support and found that social support from supervisors $(p<0.001)$, co-workers $(p<0.001)$, and family/friends ( $p=0.021)$ were associated with less severe PTSD symptoms. Their study replicated the findings by Armstrong et al. [41] that belongingness, particularly to the fire service, mitigates the negative effects of trauma exposure $(p<0.001)$ [44]. Despite the majority of studies did not specify whether social support came from family members, friends, supervisors, or co-workers when reporting its effects on the perception of stress, we propose this division, as organizational support embraces the feeling of belongingness and camaraderie.

In the last few years, an attempt to identify the main risk and protective factors for the development of PTSD and other stress-related diseases in specific populations, such as firefighters, has been observed. The findings in this field indicate that there are some factors for the development of stress-related diseases which may be considered for the general population (type, severity and exposure time to a traumatic event and social support), and others that take greater importance within certain contexts, namely the fear of stigma, the need to meet organizational expectations, the sense of camaraderie, and the occupational conditions $[10,15,16]$. On the other hand, while societal expectations were cited as relevant in the perception and interpretation the firefighters have of the event [29], the pressure and lack of recognition of their efforts by the population /society were not considered by the identified studies. Seeing as the way of perceiving the event is influenced by the reaction and interpretation of those who surround the victim $[15,20,25]$, professionals who work in crises and catastrophes must face the expectations of the whole society. The different symptomatic repertoires obey cultural norms and prescriptions, the expectations of approval or disapproval, legitimation or guilt. It is evident that firefighters are used to dealing with physical discomfort, unpredictability, the pressure and expectation of society and their departments, the fear of the victims and their own fears. However, being prepared to face extreme situations is not synonymous with being immune to traumatic stress $[15,16]$.

\section{Conclusions}

Most studies began by mentioning the scarcity of research on topics related to traumatic stress in firefighters. The analyzed articles varied in the focus chosen to address the consequences of repeated exposure to critical incidents, ranging from alcohol abuse [26,49] and suicidal ideation and behaviors $[10,11,16,35]$ to the influence of social support and organizational belongingness [41], and post-traumatic growth [36,38]. Regardless of the approach, all studies agreed that professionals who work in crisis and catastrophe scenarios are continually exposed to potentially traumatic events, configuring a high-risk group for the development of stress-related diseases $[14,15,25]$. 
However, the gaps mentioned in most studies remain due to the lack of longitudinal studies comparing firefighter samples, including clinical monitoring, which does not allow the reliability of the prevalence rate of PTSD and other stress-related diseases among firefighters. The reasons for the use of cross-sectional research with self-report questionnaires are usually justified by being preliminary surveys aiming to encourage the discussion and interest of other researchers, advertising the need to replicate the research in larger samples, including control groups and with more appropriate techniques to the specificities intended to be investigated [10,11,13,16,20,35,41,49,54].

Following the recommendations of the articles included in this systematic review, we agree that longitudinal studies are essential, especially with repeated measures and comparative groups in order to validate the findings so far. The current study, in addition to encouraging future research in this field, provides a relational model with variables that seem to interfere with the consequences of stress exposure, which may be a substantial instrument for empirical studies. Thus, we consider that the next step should be to test this model using empirical data. Furthermore, knowing the strength that each factor included in the proposed model exerts on the perception of stress, and thus in the choice of coping strategies, may be advantageous for the development of a stress-management intervention program inside fire departments, as well as to delineate a treatment considering the specificities of these population.

Supplementary Materials: The following are available online at http://www.mdpi.com/2624-8611/2/1/8/s1, Figure S1: PRISMA flow diagram, Figure S2: Graphic of Publications on PTSD and Firefighters 1980-2019, Table S1: Summary of studies on PTSD and stress-related diseases in firefighters, Table S2: Assessment of risk of bias in individual studies.

Author Contributions: Conceptualization, J.P.B., R.P., and M.J.Q.; methodology, J.P.B. and R.P.; formal analysis, J.P.B.; investigation, J.P.B. and R.P.; resources, J.P.B. and R.P.; data curation, J.P.B.; writing-original draft preparation, J.P.B. writing—review and editing, J.P.B. and R.P.; visualization, J.P.B.; supervision, R.P. and M.J.Q.; project administration, R.P.. All authors have read and agreed to the published version of the manuscript.

Funding: This research received no external funding.

Conflicts of Interest: The authors declare no conflict of interest.

\section{References}

1. Psarros, C.; Theleritis, C.; Kokras, N.; Lyrakos, D.; Koborozos, A.; Kakabakou, O.; Tzanoulinos, G.; Katsiki, P.; Bergiannaki, J.D. Personality characteristics and individual factors associated with PTSD in firefighters one month after extended wildfires. Nord. J. Psychiatry 2018, 72, 17-23. [CrossRef] [PubMed]

2. Brooks, S.K.; Dunn, R.; Amlôt, R.; Greenberg, N.; Rubin, J. Social and occupational factors associated with psychological distress and disorder among disaster responders: A systematic review. BMC Psychol. 2016, 4, 1-13. [CrossRef] [PubMed]

3. Fraess-Phillips, A.; Wagner, S.; Harris, R. Firefighters and traumatic stress: A review. Int. J. Emerg. Serv. 2017, 6, 67-80. [CrossRef]

4. Stanley, I.H.; Hom, M.A.; Joiner, T.E. A systematic review of suicidal thoughts and behaviors among police officers, firefighters, EMTs, and paramedics. Clin. Psychol. Rev. 2016, 44, 24-44. [CrossRef]

5. Lowe, S.R.; Blachman-Forshay, J.; Koenen, K.C. Trauma as a Public Health Issue: Epidemiology of Trauma and Trauma-Related Disorders. In Evidence Based Treatments for Trauma-Related Psychological Disorders: A Practical Guide for Clinicians; Schnyder, U., Cloitre, M., Eds.; Springer: Zurich, Switzerland, 2015; pp. 11-40.

6. Association, A.P. Diagnostic and Statistical Manual of Mental Disorders: Fifth edition DSM-5 ${ }^{\mathrm{TM}}$; American Psychiatric Association Publishing: Washington, DC, USA, 2013.

7. Brewin, C.R.; Andrews, B.; Valentine, J.D. Meta-Analysis of Risk Factors for Posttraumatic Stress Disorder in Trauma-Exposed Adults. J. Consult. Clin. Psychol. 2000, 68, 748-766. [CrossRef]

8. Institute of Medicine. Posttraumatic Stress Disorder: Diagnosis and Assessment; The National Academies Press: Washington, DC, USA, 2006. [CrossRef]

9. Liberati, A.; Altman, D.G.; Tetzlaff, J.; Mulrow, C.; Gøtzsche, P.C.; Ioannidis, J.P.; Clarke, M.; Devereaux, P.J.; Kleijnen, J.; Moher, D. The PRISMA Statement for Reporting Systematic Reviews and Meta-Analyses of 
Studies That Evaluate Health Care Interventions: Explanation and Elaboration. PLoS Med. 2009, 6, e1000100. [CrossRef]

10. Bartlett, B.A.; Jardin, C.; Martin, C.; Tran, J.K.; Buser, S.; Anestis, M.D.; Vujanovic, A.A. Posttraumatic stress and suicidality among firefighters: The moderating role of distress tolerance. Cogn. Ther. Res. 2018, 42, 483-496. [CrossRef]

11. Boffa, J.W.; Stanley, I.H.; Hom, M.A.; Norr, A.M.; Joiner, T.E.; Schmidt, N.B. PTSD symptoms and suicidal thoughts and behaviors among firefighters. J. Psychiatr. Res. 2017, 84, 277-283. [CrossRef]

12. Katsavouni, F.; Bebetsos, E.; Malliou, P.; Beneka, A. The relationship between burnout, PTSD symptoms and injuries in firefighters. Occup. Med. 2016, 66, 32-37. [CrossRef]

13. Jo, I.; Lee, S.; Sung, G.; Kim, M.; Lee, S.; Park, J.; Lee, K. Relationship between burnout and PTSD symptoms in firefighters: The moderating effects of a sense of calling to firefighting. Int. Arch. Occup. Environ. Health 2018, 91, 117-123. [CrossRef]

14. Brazil, A. Exploring Critical Incidents and Postexposure Management in a Volunteer Fire Service. J. Aggress. Maltreatment Trauma 2017, 26, 244-257. [CrossRef]

15. Kim, J.E.; Dager, S.R.; Jeong, H.S.; Ma, J.; Park, S.; Kim, J.; Choi, Y.; Lee, S.L.; Kang, I.; Ha, E.; et al. Firefighters, posttraumatic stress disorder, and barriers to treatment: Results from a nationwide total population survey. PLoS ONE 2018, 13, e0190630. [CrossRef] [PubMed]

16. Boffa, J.W.; Stanley, I.H.; Smith, L.J.; Mathes, B.M.; Tran, J.K.; Buser, S.J.; Schmidt, N.B.; Vujanovic, A.A. Posttraumatic Stress Disorder Symptoms and Suicide Risk in Male Firefighters: The mediating role of anxiety sensitivity. J. Nerv. Ment. Dis. 2018, 206, 179-186. [CrossRef] [PubMed]

17. Stanley, I.H.; Boffa, J.W.; Hom, M.A.; Kimbrel, N.A.; Joiner, T.E. Differences in psychiatric symptoms and barriers to mental health care between volunteer and career firefighters. Psychiatry Res. 2017, 247, $236-242$. [CrossRef]

18. Carpenter, T.P.; Pennington, M.L.; Seebeck, J.; Gomez, D.R.; Denman, T.C.; Kimbrel, N.A.; Cammarata, C.M.; Leto, F.; Ostiguy, W.J.; Gulliver, S.B. Dispositional self-forgiveness in firefighters predicts less help-seeking stigma and fewer mental health challenges. Stigma Health 2020, 5, 29-37. [CrossRef]

19. Gulliver, S.B.; Pennington, M.L.; Torres, V.A.; Steffen, L.E.; Mardikar, A.; Leto, F.; Ostiguy, W.; Zimering, R.T.; Kimbrel, N.A. Behavioral health programs in fire service: Surveying access and preferences. Psychol. Serv. 2019, 16, 340-345. [CrossRef]

20. Armstrong, D.; Schakespeare-Finch, J.; Shochet, I. Predicting post-traumatic growth and post-traumatic stress in firefighters. Aust. J. Psychol. 2014, 66, 38-46. [CrossRef]

21. Bartlett, B.A.; Smith, L.J.; Lebaut, A.; Tran, J.K.; Vujanovic, A. PTSD symptom severity and impulsivity among firefighters: Associations with alcohol use. Psychiatry Res. 2019, 278, 315-323. [CrossRef]

22. Bastug, G.; Ergul-Topcu, A.; Ozel-Kizil, E.T.; Ergun, O.F. Secondary Traumatization and Related Psychological Outcomes in Firefighters. J. Loss Trauma 2019, 24, 143-158. [CrossRef]

23. Haraldsdóttir, H.A.; Gudmundsdóttir, D.; Romano, E.; Póroardóttir, E.B.; Guomundsdóttir, B.; Elklit, A. Volunteers and professional rescue workers: Traumatization and adaptation after an avalanche disaster. J. Emerg. Manag. 2014, 12, 457-466. [CrossRef]

24. Kim, J.I.; Park, H.; Kim, J.H. The mediation effect of PTSD, perceived job stress and resilience on the relationship between trauma exposure and the development of depression and alcohol use problems in 7151 Korean firefighters: A cross-sectional study. J. Affec. Disord. 2018, 229, 450-455. [CrossRef] [PubMed]

25. Lee, J.H.; Lee, D.; Kim, J.; Jeon, K.; Sim, M. Duty-Related Trauma Exposure and Posttraumatic Stress Symptoms in Professional Firefighters. J. Trauma Stress 2017, 30, 133-141. [CrossRef] [PubMed]

26. Paulus, D.J.; Vujanovic, A.A.; Schuhmann, B.B.; Smith, L.J.; Tran, J. Main and interactive effects of depression and posttraumatic stress in relation to alcohol dependence among urban male firefighters. Psychiatry Res. 2017, 251, 69-75. [CrossRef] [PubMed]

27. Jahnke, S.A.; Poston, W.S.; Haddock, C.K.; Murphy, B. Firefighting and mental health: Experiences of repeated exposure to trauma. Work 2016, 53, 737-744. [CrossRef]

28. Yip, J.; Zeig-Owens, R.; Hall, C.B.; Webber, M.P.; Olivieri, B.; Schwartz, T.; Kelly, K.J.; Prezant, D.J. Health Conditions as Mediators of the Association Between World Trade Center Exposure and Health-Related Quality of Life in Firefighters and EMS Workers. J. Occup. Environ. Med. 2016, 58, 200-206. [CrossRef]

29. Kehl, D.; Knuth, D.; Hulse, L.; Schmidt, S. Posttraumatic Reactions among Firefighters after Critical Incidents: Cross-National Data. J. Aggress. Maltreatment Trauma 2014, 23, 842-853. [CrossRef] 
30. Lee, J.S. Perceived social support functions as a resilience in buffering the impact of trauma exposure on PTSD symptoms via intrusive rumination and entrapment in firefighters. PLoS ONE 2019, 14, e0220454. [CrossRef]

31. Pinto, R.J.; Henriques, S.P.; Jongenelen, I.; Carvalho, C.; Maia, Â.C. The Strongest Correlates of PTSD for Firefighters: Number, Recency, Frequency, or Perceived Threat of Traumatic Events? J. Trauma Stress 2015, 28, 434-440. [CrossRef]

32. Smith, L.J.; Paulus, D.J.; Gallagher, M.W.; Norman, S.B.; Tran, J.; Vujanovic, A. Perceived stress and probable alcohol misuse in firefighters: The role of posttraumatic stress. J. Stress Manag. 2019, 26, 367-377. [CrossRef]

33. Lee, J.S.; Ahn, Y.S.; Jeong, K.S.; Chae, J.H.; Choi, K.S. Resilience buffers the impact of traumatic events on the development of PTSD symptoms in firefighters. J. Affec. Disord. 2014, 162, 128-133. [CrossRef]

34. Makara-Studzinska, M.; Golonka, K.; Izydorczyk, B. Self-Efficacy as a Moderator between Stress and Professional Burnout in Firefighters. Int. J. Environ. Res. Public Health 2018, 16, 183. [CrossRef] [PubMed]

35. Martin, C.E.; Tran, J.K.; Buser, S.J. Correlates of suicidality in firefighters/EMS personnel. J. Affec. Disord. 2017, 208, 177-183. [CrossRef] [PubMed]

36. Sattler, D.N.; Boyd, B.; Kirsch, J. Trauma-exposed Firefighters: Relationships among Posttraumatic Growth, Posttraumatic Stress, Resource Availability, Coping and Critical Incident Stress Debriefing Experience. Stress Health 2014, 30, 356-365. [CrossRef] [PubMed]

37. Yun, J.A.; Ahn, Y.S.; Jeong, K.S.; Joo, E.J.; Choi, K.S. The Relationship between Chronotype and Sleep Quality in Korean Firefighters. Clin. Psychopharmacol. Neurosci. 2015, 13, 201-208. [CrossRef]

38. Oginska-Bulik, N.; Kobylarczyk, M. Association between resiliency and posttraumatic growth in firefighters: The role of stress appraisal. Int. J. Occup. Saf. Erg. 2016, 22, 40-48. [CrossRef]

39. Shrira, A.; Shmotkin, D.; Palgi, Y.; Soffer, Y.; Hamama, Y.R.; Tal-Katz, P.; Ben-Ezra, M.; Benight, C.C. How Do Meaning in Life and Positive Affect Relate to Adaptation to Stress? The Case of Firefighters Following the Mount Carmel Forest Fire. Isr. J. Psychiatry Relat. Sci. 2015, 52, 68-70.

40. Yang, S.K.; Ha, Y. Predicting Posttraumatic Growth among Firefighters: The Role of Deliberate Rumination and Problem-Focused Coping. Int. J. Environ. Res. Public Health 2019, 16, 3879. [CrossRef]

41. Armstrong, D.; Shakespeare-Finch, J.; Shochet, I. Organizational Belongingness Mediates the Relationship between Sources of Stress and Posttrauma Outcomes in Firefighters. Psychol. Trauma 2016, 8, 343-347. [CrossRef]

42. Huang, J.; Wang, X.; Li, W.; An, Y. The relationship between conscientiousness and posttraumatic stress disorder among young Chinese firefighters: The mediating effect of perceived social support. Psychiatry Res. 2019, 273, 450-455. [CrossRef]

43. Wagner, S.; Pasca, R.; Crosina, J. Hostility in firefighters: Personality and mental health. Int. J. Emerg. Serv. 2016, 5, 6-17. [CrossRef]

44. Stanley, I.H.; Hom, M.A.; Chu, C.; Dougherty, S.P.; Gallyer, A.J.; Spencer-Thomas, S.; Shelef, L.; Fruchter, E.; Comtois, K.A.; Gutierrez, P.M.; et al. Perceptions of belongingness and social support attenuate PTSD symptom severity among firefighters: A multistudy investigation. Psychol Serv. 2019, 16, 543-555. [CrossRef]

45. Skeffington, P.M.; Rees, C.S.; Mazzucchelli, T. Trauma exposure and post-traumatic stress disorder within fire and emergency services in Western Australia. Aust. J. Psychol. 2016, 69, 20-28. [CrossRef]

46. Levy-Gigi, E.; Bonanno, G.A.; Shapiro, A.R.; Richter-Levin, G.; Kéri, S.; Sheppes, G. Emotion Regulatory Flexibility Sheds Light on the Relationship Between Repeated Traumatic Exposure and Posttraumatic Stress Disorder Symptoms. Clin. Psychol. Sci. 2015, 4, 28-39. [CrossRef]

47. Park, H.; Kim, J.I.; Oh, S.; Kim, J.H. The impact of emotional labor on the severity of PTSD symptoms in firefighters. Compr. Psychiatry 2018, 83, 53-58. [CrossRef] [PubMed]

48. Park, H.; Kim, J.I.; Min, B.; Oh, S.; Kim, J.H. Prevalence and correlates of suicidal ideation in Korean firefighters: A nationwide study. BMC Psychiatry 2019, 19, 428. [CrossRef]

49. Tomaka, J.; Magoc, D.; Morales-Monks, S.M.; Reyes, A.C. Posttraumatic Stress Symptoms and Alcohol-Related Outcomes among Municipal Firefighters. J. Trauma Stress 2017, 30, 416-424. [CrossRef]

50. Zegel, M.; Tran, J.; Vujanovic, A. Posttraumatic stress, alcohol use, and alcohol use motives among firefighters: The role of distress tolerance. Psychiatry Res. 2019, 282, 112633. [CrossRef]

51. Lee, J.H.; Park, S.; Sim, M. Relationship between ways of coping and posttraumatic stress symptoms in firefighters compared to the general population in South Korea. Psychiatry Res. 2018, 270, 649-655. [CrossRef] 
52. Bing-Canar, H.; Ranney, R.M.; McNett, S.; Tran, J.; Berenz, E.C.; Vujanovic, A. Alcohol Use Problems, Posttraumatic Stress Disorder, and Suicide Risk Among Trauma-Exposed Firefighters. J. Nerv. Ment. Dis. 2019, 207, 192-198. [CrossRef]

53. Kim, J.I.; Park, H.; Kim, J.H. Alcohol use disorders and insomnia mediate the association between PTSD symptoms and suicidal ideation in Korean firefighters. Depress. Anxiety 2018, 35, 1095-1103. [CrossRef]

54. Milligan-Saville, J.S.; Paterson, H.M.; Harkness, E.L.; Marsh, A.M.; Dobson, M.; Kemp, R.I.; Bryant, R.A.; Harvey, S.B. The Amplification of Common Somatic Symptoms by Posttraumatic Stress Disorder in Firefighters. J. Trauma Stress 2017, 30, 142-148. [CrossRef] [PubMed]

55. Straud, C.; Henderson, S.N.; Vega, L.; Black, R.; Van Hasselt, V. Resiliency and Posttraumatic Stress Symptoms in Firefighters Paramedics: The Mediating Role of Depression, Anxiety, and Sleep. Traumatology 2018, 24, 140-147. [CrossRef]

56. Paltell, K.C.; Bing-Canar, H.; Ranney, R.M.; Tran, J.; Berenz, E.C.; Vujanovic, A. Anxiety Sensitivity Moderates the Effect of Posttraumatic Stress Disorder Symptoms on Emotion Dysregulation among Trauma-Exposed Firefighters. J. Psychopathol. Behav. Asess. 2019, 41, 524-535. [CrossRef]

57. Khumtong, C.; Taneepanichskul, N. Posttraumatic stress disorder and sleep quality among urban firefighters in Thailand. Nat. Sci. Sleep 2019, 11, 123-130. [CrossRef]

58. Kim, W.; Bae, M.; Chang, S.J.; Yoon, J.H.; Jeong, D.Y.; Hyun, D.S.; Ryu, H.Y.; Park, K.S.; Kim, M.J.; Kim, C. Effect of Burnout on Post-traumatic Stress Disorder Symptoms Among Firefighters in Korea: Data From the Firefighter Research on Enhancement of Safety \& Health (FRESH). J. Prev. Med. Public Health 2019, 52, 345-354. [CrossRef]

59. Kim, M.J.; Jeong, Y.; Choi, Y.S.; Seo, A.R.; Ha, Y.; Seo, M.; Park, K.S. The Association of the Exposure to Work-Related Traumatic Events and Work Limitations among Firefighters: A Cross-Sectional Study. Int. J. Environ. Res. Public Health 2019, 16, 756. [CrossRef]

60. Noor, N.; Pao, C.; Dragomir-Davis, M.; Tran, J.; Arbona, C. PTSD symptoms and suicidal ideation in US female firefighters. Occup. Med. 2019, 69, 577-585. [CrossRef]

(C) 2020 by the authors. Licensee MDPI, Basel, Switzerland. This article is an open access article distributed under the terms and conditions of the Creative Commons Attribution (CC BY) license (http://creativecommons.org/licenses/by/4.0/). 